\title{
Expansión y presencia de la radio libre en Chiapas, un fenómeno de la globalización
}

Recibido: 02 de septiembre de 2014
Aceptado: 24 de marzo de 2015
Publicado: 30 de octubre de 2015

\author{
Sarelly Martínez Mendoza \\ sarellym@gmail.com
}

Francisco Cordero Fernández

fcorderof@gmail.com

Hugo Villar Pinto

havp36@hotmail.com

Universidad Autónoma de Chiapas (México)

Resumen: En Chiapas, Estado fronterizo del sur de México, en 2002 empezaron a surgir radios libres, también conocidas como ilegales, "piratas" o no concesionadas. En 2014, funcionan 130 de estas radiodifusoras, en su mayoría religiosas (68), seguidas por comerciales no concesionadas (41), comunitarias (11), zapatistas (5), municipales (3) y partidistas (2). El objetivo de este trabajo es identificar a estas radiodifusoras, describir su barra programática y formas de operación. A través de entrevistas y monitoreo de programación, principalmente, se ha podido comprender la compleja red de radiocomunicación libre que opera en esta entidad fronteriza, y que la ubica con el número mayor de estaciones de este tipo en México. Aunque fueron localizadas 130 radios libres, la dinámica creciente que han registrado hace pensar que se seguirán multiplicando y que urge conocerlas para establecer mecanismos de diálogo y negociación con las autoridades, ya que ni los operativos policíacos ni el constante acoso de los empresarios establecidos ha cambiado la dinámica creciente. En Chiapas, la radio libre cubre con sus emisiones casi la totalidad del territorio estatal, en algunos lugares, como San Cristóbal de Las Casas, se vive una saturación en el cuadrante, mientras que en otras regiones, sobre todo en La Sierra, se convierten en las únicas ofertas radiofónicas.

Palabras clave: Radio pirata, radio libre, radiodifusión comercial, concentración radiofónica, Chiapas. 
Abstract: In Chiapas, border state in the south of Mexico, in 2002 began to emerge free radios, also known as illegal or "pirates". In 2014, work 130 of these radio stations, mostly religious (68), followed by commercial (41), community radio (11), zapatista radio (5), municipal radio (3) and partisan radio (2). The objective of this work was to identify these radio stations, describing their programmatic bar and forms of operation. Through interviews and monitoring programming, mainly, was able to understand the complex network of free radio communication, which operates in this border state, which has the greatest number of stations of this type in Mexico. Although 130 free radios were located, growing dynamics that have registered, suggests that they will continue to multiply and that it is urgent to know them, to establish mechanisms for dialogue and negotiation with the authorities. In Chiapas, the radio free covers with their emissions almost the entirety of the state territory, in some places, such as San Cristobal de Las Casas, we are experiencing a saturation in the quadrant, while in other regions, particularly La Sierra, the free radio is alone.

Key words: Pirate radio, Free Radio, Commercial broadcasting, Radio concentration, Chiapas.

\section{Introducción}

A finales del siglo XX, empezaron a emerger en Chiapas radiodifusoras que no contaban con permiso ni concesión para transmitir. Al principio fueron estaciones de corte religioso, pero después aparecieron de índole comercial, partidista y comunitaria. El escenario actual de este tipo de radiodifusoras está ubicado en la frontera sur de México, con 130 estaciones, una cifra que hay que tomar con reservas porque continuamente incrementan su número. Chiapas, de acuerdo con este dato, es el Estado que alberga el mayor número de estaciones que operan sin concesión en México y que las nombramos en este trabajo como "radios libres", con el propósito de evitar confusiones y la descalificación fácil de llamarlas "piratas", como suelen referirse a ellas los empresarios radiofónicos.

Hay que reconocer que las radios libres son parte de un fenómeno global, propiciado por el abaratamiento de las tecnologías en información y por un marco legal restrictivo que veta a pequeños empresarios y a organizaciones sociales a contar con emisoras. En Brasil, se calcula que funcionan 10000 estaciones de este tipo; en Argentina, 8000 y en España, la Asociación Española de Radio Comercial ha documentado 2279 estaciones que no disponen de licencia de emisión, "lo que significa que existe el doble de radios ilegales que las que disponen de autorización administrativa y cumplen los requisitos establecidos por el Ministerio de Industria” (Anuncios Radios, 2008).

Según las declaraciones del que fuera presidente de la Comisión Federal de Telecomunicaciones de México, Mony de Swaan, en 2011 operaban en Chiapas 77 radiodifusoras sin permiso; en Oaxaca, 66; Guerrero, 5; Estado de México, 4; Michoacán, 3; Distrito Federal, 3; Coahuila, 2; Sonora, 2; Veracruz, 2; uno en Puebla y otro en Chihuahua. Estas radiodifusoras, abundó, eran de todo tipo, "vinculadas con iglesias y 
también otras vinculadas con delitos y narcotráfico" (Hernández Alcántara, 2011). Ante esas afirmaciones, el propósito de este trabajo ha sido mapear las estaciones al margen, así como conocer su perfil, organización y barra programática.

\section{Metodología}

La propuesta metodológica está vinculada a la teoría de los sistemas. En ese sentido, se consideran a las estaciones de radio como un subsistema de información inserto en un sistema más amplio de medios constituido por estaciones de televisión, páginas webs y periódicos. El subsistema radiofónico está integrado por estaciones legalmente establecidas y por estaciones que no han alcanzado esta categoría, pero que buscan ser reconocidas por las instancias gubernamentales. En un universo de estaciones con reconocimiento legal y otras que no están concesionadas ni permisionadas, fue necesario realizar investigación de campo, monitorear estaciones, entrevistar a personal y a directivos de las estaciones.

\section{Sobre el término "pirata"}

Los términos para referirse a las radiodifusoras que no tienen permiso ni concesión son variados. Algunos las llaman ilegales, pero lo más usual es nombrarlas como "piratas". Para Romero (2008), las radios “piratas" tienen su origen en 1937, en Alemania, cuando un grupo de socialistas que se enfrentaban con el nazismo fundaron La Emisora de la Libertad, que evitaba ser localizada porque emitía desde un barco con bandera negra. Esa tradición la continuaron comunicadores posteriores que se enfrentaron a regímenes totalitarios. En España hubo también un papel reivindicativo que impulsó la aparición de la radio libre o “pirata” (Sierra Sánchez, 2010).

Según Calleja y Solís (2007: 28) una distinción que puede hacerse respecto a las radios "piratas" es que funcionan sin autorización legal, "cuyo fin es el lucro, son negocios ilícitos de familias, personas o grupos que se benefician de este acto ilegal". Sin embargo, en esta investigación hemos optado por el término "radio libre", porque no todas las radiodifusoras que no cuentan con autorización para transmitir, comercializan sus espacios: no les interesa el lucro porque tienen otras prioridades, como conquistar conciencias, por ejemplo, que sería el caso de las radiodifusoras religiosas o transmitir un mensaje ideológico, como sucede con las radios zapatistas.

\subsection{Enfrentamiento de dos modelos}

Para Gabriel Sosa Plata, en México existen un total de 166 radios al margen y 1600 legales, de las cuales 1235 son concesionadas y 365 permisionadas; 853 son de AM y 657 de FM (ápud Bravo, 2011), aunque esta distinción solo opera para fines legales, porque en la práctica la mayoría de radios en AM efectúa transmisión espejo en FM. 
En la industria radiofónica existe una fuerte actividad concentradora. Mejía Barquera (2011) señala que el $80 \%$ de las emisoras en México es operado por 13 grupos, "lo cual ha hecho que la programación transmitida tenga un alto grado de uniformidad en varios de los elementos que la componen" desde la música, estilos de locución y formatos. Los grupos radiofónicos que destacaban por el número de estaciones que administran son Radiorama, Acir, Radio Centro, Radio Fórmula, Organización Impulsora de Radio, Sociedad Mexicana de Radio, Radiodifusoras Asociadas, MVS Radio y ABC Radio.

En Chiapas, la concentración radiofónica se repite. Las 41 radiodifusoras de FM y las 35 en AM pertenecen, en su mayoría, a dos familias: Valanci Hasson, del Grupo Radio Digital; y Simán Estefan, de Radio Núcleo, con 8 y 21 estaciones, respectivamente. Hay otros grupos que también tienen presencia en la entidad como Radiorama, con 22 estaciones; Sistema Chiapaneco de Radio y Televisión, 10; ABC Radio, 5; Narváez Rincón, 3; Instituto Mexicano de la Radio, 3; Quiñónez Armendáriz, 2, y Consejo Nacional para el Desarrollo de los Pueblos Indígenas de México, 2. En este panorama de concentración informativa local y nacional surgieron las radiodifusoras libres a principios del 2002: un fenómeno creciente que hoy alcanza 130 estaciones, lo que casi duplica a las legalmente establecidas.

Ante esta proliferación de estaciones libres, los empresarios, aglutinados en la Cámara de la Industria de la Radio y la Televisión (CIRT), presionan al gobierno para organizar operativos que permitan desmantelar a esas radiodifusoras. "Es urgente redoblar nuestros esfuerzos de colaboración con las autoridades para terminar con ese cáncer que son las 'radios piratas"', dijo Tristán Canales, representante de los empresarios radiofónicos en la 79 convención de esta organización, porque consideró que la práctica de la radiodifusión ilegal " $y$, en ocasiones, su posterior legalización, han sentado precedente negativo que no solo lesiona el desarrollo equilibrado del sector, sino que también atenta contra la legalidad que promueve el gobierno de la República” (Hernández Alcántara, 2011).

La Procuraduría General de la República atiende estos llamados y periódicamente realiza operativos a través de la Agencia Federal de Investigación (AFI) y el Ejército mexicano para desmantelar radiodifusoras libres. Aunque estos operativos se iniciaron en 2004, el año de mayores decomisos fue el 2008, cuando fueron detenidos locutores de radiodifusoras religiosas y desmantelados sus equipos en los municipios de Mapastepec, Villa Las Rosas, Comitán y Frontera Comalapa.

Radialistas de estaciones religiosas decidieron protestar. El 20 de septiembre de 2008 marcharon programadores, locutores y pastores en la ciudad de San Cristóbal de Las Casas. Los manifestantes exigieron reformas a la Ley de Radio y de Televisión con el propósito de que las denominaciones religiosas pudieran administrar estaciones de radio sin fines de lucro. Marcos Porras, presidente del Frente Unido Nacional para la Comunicación Cristiana, expresó que México, a diferencia de países de Estados Unidos, Centro y Sudamérica, no contaba con una reglamentación clara sobre las radios cristianas (Noticia Cristiana, 2008a). El pastor Esdras Alonso González, de la organización Ejército de Dios, advirtió en esa ocasión que los cristianos evangélicos iniciarían una resistencia civil en todo el Estado: "Vamos a defender las radios; por eso hacemos un llamado a los gobiernos 
federal y estatal a que cesen esos operativos, porque de lo contrario se puede violentar la región" (Custodio, 2008).

En agosto del mismo año, en un acto celebrado en Unión Juárez, los dirigentes de iglesias de Chiapas fundaron la Comisión Cristiana de Radio y Televisión del Estado, con el propósito de que ese órgano realizara labores de interlocución con el gobierno chiapaneco. En ese momento existían en Chiapas 25 estaciones religiosas, las cuales pasaron a formar parte de esta comisión. El 29 de noviembre de 2008 volvieron a marchar. El epicentro fue otra vez San Cristóbal de Las Casas en donde se concentraron más de tres mil cristianos evangélicos. Antes de la marcha, Noé Castañón, secretario de Gobierno de Chiapas, llamó al dirigente de la organización Alas de Águila Radio para informarle se suspendían los operativos y que pronto se establecerían mesas de diálogo con el gobierno federal para resolver el problema. No obstante la oferta, la marcha continuó. Además de exhibir pancartas con las frases: "AFI: en materia de inseguridad, el Evangelio es el más seguro" y "Alto a los operativos de AFI contra radios cristianas", los manifestantes exigieron no privilegiar "los intereses del monopolio radiofónico chiapaneco por encima de los intereses de las mayorías" (Noticia Cristiana, 2008b).

El entonces presidente municipal de San Cristóbal, Mariano Díaz Ochoa, participó también en la manifestación y comentó que no asistía como funcionario, sino como ciudadano. Aseguró que en el acto se respiraba, paz y tranquilidad "porque todos somos hermanos". Manifestó estar de acuerdo en que las iglesias evangélicas contaran con estaciones de radio, pero aclaró que se necesitaba que fueran reglamentadas y "que podría ser de tipo comunitario, figura establecida en la ley" (Henríquez, 2008). Como resultado de estas movilizaciones, se instaló una mesa de diálogo el 19 de diciembre de 2008 (ratificada el 9 de enero de 2009) en donde la Secretaría de Gobernación garantizó que no habría decomiso de las estaciones religiosas en Chiapas hasta que lograran los permisos respectivos. En otras palabras, desde ese momento serían toleradas. En ese momento, en México existían 90 radiodifusoras religiosas, de las cuales el $40 \%$ estaban ubicadas mayoritariamente en San Cristóbal de Las Casas.

Seis meses después, el secretario de Gobernación, Fernando Gómez Mont, informó ante empresarios de la radio y la televisión del país que decomisaría "60 estaciones 'piratas' de Chiapas" (Noticia Cristiana, 2009). Esta declaración provocó nuevamente movilizaciones de los cristianos evangélicos. El pastor José Cano, locutor de Manantial de Vida, afirmó que solo estaban esperando a que llegaran los agentes para dejar de transmitir los programas:

"Confiamos en Dios que no nos vayan a detener, porque si bien no tenemos permisos legales, tampoco estamos fomentando el narcotráfico, la violencia, el desorden social o un delito mayor, como lo hacen otras personas en los medios masivos" (ibidem).

El anuncio del funcionario quedó solo en amenaza porque ya no se han registrado más operativos de decomiso en contra de las radios religiosas. Sin embargo, las radio libres que no son religiosas siguen siendo perseguidas y sus equipos decomisados. Al respecto, el 29 de 
septiembre de 2010, la Procuraduría General de la República indicó que había desmantelado cinco estaciones que funcionaban de manera ilegal en Tuxtla Gutiérrez, Villaflores, Mapastepec y Escuintla (El Informador, 2010). El 13 de mayo de 2011, las autoridades “desactivaron" las "radioemisoras piratas” Radio Más (98.9 FM) y La Explosiva (102.9 FM), las cuales funcionaban en Comitán. El 30 de enero de 2012, fue "desarticulada" la emisora Radio San Fernando (98.3 FM), que emitía desde el municipio del mismo nombre. Y el 21 de febrero de 2014, Radio Activa de San Cristóbal de Las Casas, sufrió igual destino.

Pese a estas acciones de las autoridades mexicanas, no ha sido posible detener el rápido crecimiento de este tipo de radiodifusoras, lo que induce a pensar que la solución ante la emergencia de radios libres no se encuentra en la persecución, sino en la negociación y en el diálogo.

\subsection{Emergencia}

Las primeras radios libres que surgieron en Chiapas pertenecían al Ejército Zapatista de Liberación Nacional (EZLN). El gobierno mexicano se veía imposibilitado a controlar estas emisiones porque procedían del territorio zapatista (de algún lugar de la Selva Lacandona), comunidades rebeldes y con gobiernos autónomos en donde las autoridades nacionales no pueden ingresar. Radio Insurgente. La voz de los sin voz, comenzó a transmitir en febrero de 2002 por la banda 49 metros con 6 megahertz de potencia. Después, ocupó el dial 97.9 FM.

Un mes después, en marzo de 2002, empezó a emitir desde San Cristóbal de Las Casas la radiodifusora ciudadana Frecuencia Libre en el 99.1 FM. También por esas fechas, comenzó a funcionar Radio Activa, impulsada por el experimentado radialista Víctor Ballinas. Ese mismo año, en Motozintla, surgió la primera estación que tuvo como finalidad comercializar su espacio, Súper Buena, a través del 96.1 FM.

En el 2003, surgió Radio ChanulPom, de corte comunitario, en Chenalhó, y en el 2004 se sumaron emisoras de tipo religioso, como Palabras de Esperanza Miel y Alas de Águila Radio, en San Cristóbal; La Más Invasora, en Chicomuselo, y La Consentida, en Teopisca, ambas de tipo comerciales sin concesión. En 2005, desde territorio zapatista, comenzaron a transmitir Radio Votán Zapatista y Radio Amanecer; en Chamula, la radio comunitaria OkesNom; en Motozintla, Hits 99.7, y en Palenque, La Súper Buena. En 2006, en esa misma ciudad, surgió Tu amiga radio; en Huixtla, Radio Enlace Soconusco; en Ocosingo, Radio Cultural Vida; en San Cristóbal, Alfa y Omega; en Teopisca, Simientes del amor y la amistad; en Zinacantán, Estéreo Vida y Radio Sol de Justicia, y en Chilón, Tsumbal Xitalha. Desde entonces, las radios libres se han multiplicado hasta llegar, a principios de 2014, a 130 emisoras, lo que casi dobla al número de las legalmente establecidas.

\subsection{Presencia}

De las 15 regiones económicas en las que se divide Chiapas, solo en dos de ellas no existen todavía radios libres: región Norte y Frailesca. En contrapartida, Los Altos-Tsosil-Tseltal 
concentra 38 estaciones, es decir, un 29.2\% del total de este tipo de medios. En Los Altos, destaca San Cristóbal de Las Casas con 25 radiodifusoras, entre las que figuran cristianas, zapatistas, comunitarias, comerciales no concesionadas, concesionadas y permisionadas.

Después de Los Altos, pero con 13 estaciones, aparece la región Tulijá-tseltal-chol; sigue la región Sierra-Mariscal, con 12 radiodifusoras; Soconusco, 11; De Los Bosques, 11; Metropolitana, 8; Istmo-Costa, 7; Selva Lacandona, 6; Maya, 6; Mezcalapa, 4, y Valles, 3. Al analizar estos datos, se percibe que las regiones con mayor presencia indígena, a excepción de Soconusco, son donde existe más actividad de radios libres, pero además se relaciona con otra constante: mayor número de denominaciones religiosas.

\section{Tipología de radios libres}

En Chiapas pueden identificarse los siguientes tipos de radios libres:

- Radios religiosas.

- Radios comerciales no concesionadas.

- Radios partidistas.

- Radios municipales.

- Radios zapatistas.

- Radios comunitarias.

Las radios libres religiosas tienen como fin fundamental conquistar nuevos creyentes y mantener una red de comunicación con los miembros de sus denominaciones. Son las más abundantes en la entidad. Por su parte, las comerciales no concesionadas buscan mercantilizar sus espacios. No se diferencian de las estaciones comerciales. Al contrario, copian su estilo, barra programática y estilos de locución. Su auditorio, debido a que la mayoría está en poblaciones pequeñas, es reducido.

Las radios libres partidistas tienen su auge en los periodos electorales, por eso una vez pasada las elecciones locales desaparecen. Actualmente solo funcionan Radio Totik (del PRD) y Radio Azul (del PAN), en Venustiano Carranza. Localizamos radios municipales, aquellas que dependen de presidencias municipales y transmiten desde las alcaldías. Tienen como fin dar a conocer las actividades del cabildo y campañas de educación y de salud.

Las radios libres zapatistas dependen del Ejército Zapatista de Liberación Nacional; su programación está enfocada a dar a conocer acuerdos a las Juntas del Buen Gobierno y de los municipios autónomos. Otro tipo de estaciones son las radios comunitarias, aunque no son numerosas sí figuran en el cuadrante chiapaneco. Busca rescatar tradiciones, costumbres y sensibilizar a las personas para la conservación del ambiente. Destacan las radiodifusoras asociadas a la organización Boca de Polen.

Estos son los seis diferentes tipos de radiodifusoras libres que identificamos en el cuadrante chiapaneco, los cuales analizaremos a continuación y que tienen la siguiente presencia: 
Tabla 1: Presencia de la radio libre en Chiapas.

\begin{tabular}{|l|c|c|}
\hline \multicolumn{1}{|c|}{ TIPO DE RADIO LIBRE } & NÚMERO & PORCENTAJE \\
\hline Religiosa & 68 & 52 \\
\hline Comerciales no concesionadas & 41 & 31.5 \\
\hline Partidistas & 2 & 1.5 \\
\hline Municipales & 3 & 2.5 \\
\hline Zapatistas & 5 & 4 \\
\hline Comunitarias & 11 & 8.5 \\
\hline TOTAL & 130 & 100 \\
\hline
\end{tabular}

Fuente: Elaboración propia.

\subsection{Radios libres religiosas}

Chiapas vive una fuerte dinámica de estaciones religiosas, especialmente cristianas evangélicas, $\mathrm{y}$, en menor medida, católicas y adventistas, que suman en conjunto 68 radiodifusoras (52\% del total de radios libres), ubicadas en 32 municipios. El mayor número de estas radiodifusoras está asentado en la zona de Los Altos, en donde sobresale San Cristóbal de Las Casas con 12. Tres municipios (Huixtla, Tapachula y Tuxtla Gutiérrez) aparecen con tres estaciones, y con dos estaciones, once municipios: Arriaga, Chilón, Frontera Comalapa, Motozintla, Palenque, Ocosingo, Pantelhó, Simojovel, Tuxtla Chico y Zinacantán.

Las 68 radiodifusoras, aunque están localizadas en 32 municipios, su área de difusión abarca por lo menos el doble de esa extensión geográfica. Esto nos lleva conjeturar que más del 50\% de la geografía estatal está cubierta por emisiones radiofónicas de corte religioso. Hay, además, dos radiodifusoras guatemaltecas que esparcen su señal a gran parte del territorio estatal: Radio Santa Teresita del Niño Jesús (católica) y Estéreo Shadai (cristiana).

Estas radiodifusoras, de acuerdo con su barra programática, son de cuatro tendencias:

- Cristianas evangélicas: Fundamentalmente del protestantismo pentecostal, conformado por asambleístas, presbiterianos y nazarenos.

- Adventistas: Pertenecen a grupos para cristianos del séptimo día.

- Cristocéntricas: Emiten mensajes cristianos sin importar la denominación religiosa.

- Católicas: Emisoras de grupos, organizaciones e iglesias de índole católica. 
Tabla 2: Radios religiosas.

\begin{tabular}{|l|c|c|}
\hline \multicolumn{1}{|c|}{ TIPO DE RADIO RELIGIOSA } & NÚMERO & PORCENTAJE \\
\hline Cristiana evangélica & 49 & 72 \\
\hline Adventista & 5 & 7 \\
\hline Cristocéntrica & 8 & 12 \\
\hline Católica & 6 & 9 \\
\hline TOTAL & 68 & 100 \\
\hline
\end{tabular}

Fuente: Elaboración propia.

\subsubsection{Radiodifusoras cristianas evangélicas}

De acuerdo con el presidente de la Comisión Cristiana de Radio y Televisión del Estado de Chiapas, Hortensio Vázquez Vázquez, en la entidad existen 230 asociaciones religiosas, en su mayoría del cristianismo evangélico. Eso se refleja también en el número de radiodifusoras en donde 49, de un número de 68 religiosas, presentan un perfil cristiano evangélico (72\%). Palabras de Esperanza Miel, que inició transmisiones el 24 de febrero de 2004, es la pionera y la decana del dial cristiano. Le siguió Alas de Águila Radio, creada en diciembre de 2005, por el pastor pentecostés Esdras Alonso. A partir de 2006 inició la explosión de radios religiosas, en especial pentecostales, las cuales cubren casi la totalidad de la geografía chiapaneca.

\subsubsection{Radios adventistas}

En Chiapas existen cinco estaciones adventistas ( $7 \%$ del total de radiodifusoras religiosas), tres de las cuales están ubicadas en San Cristóbal de Las Casas, una en Copainalá y otra en Suchiapa. Su surgimiento se debe más a la iniciativa de los fieles que al interés de los dirigentes de la iglesia, quienes a pesar de contar con una estructura fuerte, capaz de financiar estaciones en varias partes del Estado, prefieren abstenerse debido a que aún no es posible establecer radiodifusoras con el permiso estatal.

San Cristóbal de Las Casas no es el principal municipio de adventistas de Chiapas, pero es donde se registra mayor actividad radiofónica. Para pueblos de fieles adventistas, como Malpaso, Tecpatán, Ocotepec, Tapalapa, Tapilula, Ixtapangajoya y Chapultenango, emite desde hace algunos meses La Voz de los Tres Ángeles desde Copainalá, que con su nombre se rinde homenaje a la estación adventista de Guatemala. Radio Alfa y Omega es la estación adventista más antigua. Inició en 2006 y transmite por la frecuencia 105, en San Cristóbal, y otra con el mismo nombre, hace lo propio en Suchiapa. 


\subsubsection{Radios cristocéntricas}

Tienen como característica fundamental no depender jerárquicamente de ninguna iglesia, no referirse a una sola doctrina y tener como eje de su discurso a Cristo y a la Biblia. 8, de las 68 emisoras religiosas, son de este tipo (12\%). Radio Vida, que transmite en la ciudad de Ocosingo por el 92.7 FM, es ejemplo de este tipo de radiodifusora. Asimismo, por su número de oyentes y el área que cubre, es la emisora religiosa más importante de Chiapas. La mayor novedad de esta investigación fue encontrar a este tipo de radiodifusoras que no pertenecen a una sola denominación, pero que dan cabida a fieles y a pastores de todas las iglesias.

\subsubsection{Radios católicas}

La incursión de la iglesia católica en la gestión y operación de estaciones de radio en Chiapas ha sido tardía. Su estación, Radio Tepeyac, apareció recién en junio de 2012. Para entonces, el cuadrante de FM ya estaba prácticamente copado por emisiones protestantes. "Por tratar de ser muy legales, ya nos quedamos muy atrás", reconoció el obispo Felipe Arizmendi Esquivel, en referencia a la incursión de la iglesia católica en la radio (YouTube, 2011).

De hecho, Radio Tepeyac surgió con el propósito de disputar el mercado de las conciencias. Intentó, primero, respetar el marco legal, con emisiones a través de Internet, pero su público objetivo quedaba distante, así que decidió establecerse en la frecuencia modulada. En su inauguración (1/IX/2011), cuando empezó a emitir solamente por la web, Arizmendi Esquivel señaló que la estación "en parte fue creada por la competencia de los hermanos protestantes que tienen muchas emisoras en las cuales se dedican a atacarnos" (ibídem).

Debido a lo complicado que puede resultar para la iglesia católica defender a una estación que no tiene permiso, el obispo ha expresado que quienes operan la radiodifusora son laicos: "Radio Tepeyac no es una emisora oficial de la diócesis de San Cristóbal de Las Casas, sino de laicos responsables de su misión evangelizadora" (Gómez Mena, 2011). En todo caso, desde la inauguración, el dirigente católico insistió en que buscarían la autorización de Cofetel para transmitir por FM. En junio de 2012, aún sin la anuencia de esa institución, comenzaron a invadir las ondas hertzianas a través de la frecuencia 93.3.

Aparte de Radio Tepeyac de San Cristóbal, en Chiapas transmiten cinco radiodifusoras católicas más ( $9 \%$ del total de radios religiosas): Radio Católica y Cultural Comitán, Misericordia Radio Tepeyac, Radio El Pescador, Radio Católica Santísima Trinidad de La Trinitaria y Radio Católica Comalapa.

\subsection{Radio comercial no concesionada}

Es la que más se acerca a la radio "pirata", según la consideración que realizan Calleja y Solís (2007), al indicar que una radiodifusora de este tipo es la que lucra, de manera ilegal, del espacio radioeléctrico. Este tipo de radiodifusora no presenta características distintivas 
de la radio comercial concesionada: copia sus formatos, la manera de vender paquetes publicitarios y el estilo de comunicación de sus locutores.

Desde luego, que los dueños de este tipo de radiodifusoras no aceptan el calificativo de "piratas", porque indican que no le están robando la señal a nadie y que contribuyen con las autoridades hacendarias mediante cuotas de IVA, ISR e impuestos sobre nóminas. Piratería, dice Víctor Ballinas, propietario de Radio Activa de San Cristóbal, es "apropiarse de la obra intelectual de otros, pero la producción es nuestra, no se la quitamos a nadie" (Martínez y otros, 2013: 26). El mismo razonamiento expresa Rodríguez Damas, director de Radio 103.1 $F M$ de Palenque, quien no entiende por qué les llaman "piratas", si realizan contribuciones fiscales, crean fuentes de trabajo y han solicitado una concesión legal, pero "el monopolio radiofónico, concentrado en unas cuantas manos no los ha negado" (ibídem: 27).

En el mapeo y clasificación de este tipo de radiodifusoras, que lucran con el espacio radioeléctrico, encontramos 41 radiodifusoras de este tipo (31.5\% del total de radios libres), 4 de ellas, que si bien presentan contenidos culturales, venden y viven de los anuncios comerciales. Al analizar a estas radiodifusoras, el primer dato significativo es que muchas tienen el mismo número de frecuencia. Por ejemplo, en Acala y Escuintla, municipios separados por 200 kilómetros, comparten la frecuencia 90.9 FM.

Debido a la presencia que llegan a tener en sus regiones, las mismas instituciones oficiales, tanto municipales como estatales y federales, emplean estos medios para transmitir campañas de protección civil, de educación y de vacunación. El estilo de "locutar", como refieren los locutores a su actividad de comunicación, es muy parecido al de la radio comercial, pero con mayor improvisación, porque los comunicadores son generalmente jóvenes, entre los 16 y 20 años, que laboran en sus ratos libres y por temporadas.

Estas radiodifusoras, contra la postura expresada por los empresarios radiofónicos, cubren territorios y necesidades que no satisface la radio comercial. La Cafetalera y La Poderosa de la Sierra transmiten, por ejemplo, desde la Sierra Madre de Chiapas, una región que no es atendida por la radio concesionada. Eso no sucede en todas las regiones de Chiapas. San Cristóbal sufre una saturación de frecuencias, en donde un pequeño mercado se lo disputan radiodifusoras concesionadas, comerciales no concesionadas, religiosas, zapatistas y comunitarias.

El fin comercial de estas radiodifusoras entra en conflicto con las estaciones concesionadas. De ahí que sean el primer objetivo de los empresarios radiofónicos, quienes repetidamente interponen demandas en contra de estas.

\subsection{Radios partidistas}

Otro tipo de radiodifusoras detectadas fueron las partidistas, las cuales tienen una baja presencia actualmente, porque no se registran elecciones, pero en los periodos electorales incrementan su incidencia. En Chiapas solo se observa su participación en el municipio de 
Venustiano Carranza, en donde una lleva por nombre Radio Totik, identificada con el PRD, y la otra, Radio Azul, simpatizante del PAN. La incursión y presencia de estas emisoras es una novedad, porque surgieron en una coyuntura política especial y, al paso del tiempo, se han convertido más en radiodifusoras de corte comercial que en partidistas.

\subsection{Radios municipales}

Una novedad en Chiapas es encontrar radiodifusoras que dependen directamente de las presidencias municipales y que están al servicio de los alcaldes. Los colaboradores cobran honorarios en el ayuntamiento y la barra programática responde a las necesidades del cabildo. Los estudios, el equipo y la antena de transmisión se localizan en el edificio de los ayuntamientos. Por estas características a estas radiodifusoras las clasificamos como “municipales”. Están ubicadas en Acala, Cintalapa y Pueblo Nuevo Solistahuacán.

En estos casos, los alcaldes se han convertido en los propios promotores de estas radiodifusoras: las instalan y las mantienen con recursos públicos. Aunque son pocas, estas radiodifusoras deben tomarse en cuenta por el carácter del propietario: una autoridad local que viola los reglamentos de una autoridad nacional. El propósito no es, desde luego, rentabilizar el medio, sino contar con un puente entre la presidencia municipal y los ciudadanos. Así, estas radiodifusoras se convierten en el vehículo fundamental de los ciudadanos para enterarse de disposiciones municipales y pagos de apoyos estatales y federales como Amanecer, Oportunidades y Procampo.

\subsection{Radios zapatistas}

Uno de los pilares del EZLN fue, desde 1982, su sistema de comunicación interna. Las bases zapatistas poseían redes profundas y complejas de difusión. La principal herramienta que emplearon en un principio fue la radio de banda civil. A través de ella se conectaron las comunidades y los milicianos. En este trabajo se lograron registrar cinco radiodifusoras zapatistas, las cuales operan en territorio rebelde y están sujetas a las juntas de buen gobierno de los Municipios Autónomos Rebeldes Zapatistas (Marez).

En su página oficial (www.radioinsurgente.org), el Ejército Zapatista de Liberación Nacional reconoce la existencia de dos radiodifusoras que transmiten por frecuencia modulada: Radio Amanecer y Radio Resistencia, las cuales se ubican en San Andrés Larráinzar. El EZLN también cuenta con Radio Insurgente. La voz de los sin voz, una estación que "sube" contenidos a la red y que realiza emisiones por onda corta (6.0 Mhz en la banda de 49 metros) los sábados de tres a cuatro de la tarde.

Además de Radio Amanecer, Radio Resistencia y Radio Insurgente, el EZLN posee Radio KomanIlel, Mirada colectiva (99.1 FM) y Radio Votan Zapata. Cooperación sin mando (89.1 FM). La programación de estas radiodifusoras se conforma principalmente por discursos del subcomandante Marcos, corridos de la Revolución y música grabada por 
militantes del EZLN: "Los grupos musicales de las comunidades en resistencia llegan para grabar en el estudio sin tener que pagar", indica Producciones Radio Insurgente y agrega: "por primera vez grupos musicales indígenas y zapatistas tienen la oportunidad de grabar su música, dando así una difusión más amplia a la música tradicional de las comunidades y a los corridos zapatistas" (Radio Insurgente, 2015).

Estas radiodifusoras son atendidas por mujeres y hombres de las comunidades quienes, de manera voluntaria o por nombramiento de sus pueblos, desempeñan la función de operadores, locutores y productores radiofónicos (Enlace Zapatista, 2011). Las emisoras transmiten en castellano, tsotsil, tseltal, tojolabal y ch'ol. Su portal de Internet ofrece, además, contenidos en cuatro idiomas extranjeros: inglés, italiano, alemán y francés.

\subsection{Radios comunitarias}

Debido al apoyo que han tenido recientemente las radios comunitarias, prácticamente todas las radios libres en Chiapas se consideran a sí mismas como comunitarias. Sin embargo, estas últimas tienen características muy definidas, como es la participación de la comunidad en su gestión, organización y diseño de la barra programática. Otorga, además, un poder decisivo a sus miembros, promueve tradiciones, música y festividades de la localidad.

La Red de Comunicadores Boca de Polen es la pionera en el establecimiento de radios comunitarias, al impulsar el 2003 la creación de Radio Chanul Pom, en Chenalhó. Hizo lo propio en Chilón con Radio Jlumaltic y con Radio Unidad Guaquitepec. Otras radiodifusoras intentan responder a las características de radio comunitaria, como Tsumbal Xitalha, de Chilón; Radio Mezcalapa y Radio Juventud, de Copainalá; Mega FM, de Salto de Agua; Frecuencia Libre, de San Cristóbal; Radio Xkuxlejal Jlumaltik, de Tenejapa; Radio Saraguato, de Palenque, y OkesNom, de Chamula. El 8.5\% de las radios libres en Chiapas son de tipo comunitario o buscan responder a ese poder de encuentro con la comunidad.

\section{Auditorio}

Las radiodifusoras al margen cuentan con su propio auditorio. En su mayoría, lo han encontrado en su comunidad, sobre todo en aquellos radioescuchas que sentían muy distantes las emisiones que provenían de estaciones ubicadas en ciudades. Con la radiodifusora, instalada en el pueblo, la comunicación, las referencias y los giros se hacen más cercanos y conocidos; además, es más fácil y accesible enviar un mensaje al teléfono móvil del locutor para solicitar canciones o para saludar a parientes y amigos.

Auditorios ignorados por las radios comerciales, sobre todo en comunidades indígenas de la Selva o en la Sierra Madre de Chiapas, han encontrado en las radios al margen un espacio de comunicación y convivencia. En otros lugares, se registra una disputa por el auditorio con la radio comercial de manera directa y frontal. En San Cristóbal, 25 estaciones de perfil religioso, comercial no concesionado, zapatista, comunitario, estatal, concesionado y 
comercial, buscan radioescuchas entre la población, estimada en 200 mil habitantes. Hay, desde luego, una saturación del cuadrante.

Aunque todas las radiodifusoras quieren ser escuchadas, el enfrentamiento mayor que viven los empresarios radiofónicos es con las radios comerciales no concesionadas, ubicadas en zonas urbanas, porque en su "parrilla" presentan música, programas y anuncios similares. Aquí se distingue, a un radioescucha móvil, que aunque cuenta con una estación de preferencia, no duda en cambiar de dial, con el fin de explorar nuevas ofertas radiales.

Los radioescuchas con perfiles de tipo religioso o ideológico presentan mayor arraigo por las estaciones porque pertenecen a sus propios grupos, asociaciones o iglesias, que no eran atendidas por las radios de corte comercial. Es menos itinerante, porque escuchan la radiodifusora que realizan los miembros de su congregación; siguen las prédicas de sus pastores y de sus "hermanos" de denominación. No migran a otras estaciones porque se abstienen de escuchar música comercial o programas que no contemplen aspectos religiosos.

Las radiodifusoras zapatistas, con un perfil ideológico muy definido y vinculado a organizaciones sociales, transmiten música tradicional y discursos "revolucionarios", que encuentra a su auditorio en simpatizantes o militantes con el movimiento. Las municipales priorizan los mensajes de las alcaldías; las comunitarias, la buena convivencia, y las partidistas, los contenidos que beneficien a su partido político.

\section{Anuncios}

Las radios al margen brindan espacio a los anuncios, pero estos no constituyen un elemento fundamental para el sostenimiento de las radiodifusoras. Es cierto que juegan un papel importante dentro de las radios comerciales no concesionadas, pero no así en las de otros perfiles. Como hemos indicado, la programación de las radios comerciales sin concesión es muy parecida a la radio comercial, y por consecuencia, disputa un auditorio similar. Su fin es el mismo: obtener utilidades, y esas utilidades serán mayores en la medida que cuenten con un mayor número de radioescuchas.

Y es aquí donde se presenta un aspecto que preocupa a los empresarios radiofónicos: en San Cristóbal de Las Casas, por ejemplo, las radiodifusoras comerciales no concesionadas ofrecen los anuncios a menor precio que en las emisoras legalmente establecidas. Es, en ese sentido, una competencia desleal. Con las otras radiodifusoras, los anuncios comerciales prácticamente no existen, porque no tienen como finalidad obtener recursos a través de la venta de programas o publicidad, sino fortalecer sus agrupaciones.

Las religiosas, por ejemplo, buscan mantener unidas a su congregación y captar nuevos adeptos. Los recursos para pagar los gastos de operación provienen de las iglesias, de "radio-maratones" y aportaciones voluntarias de los radioescuchas, pero no por la venta de anuncios. Radio Cultural Vida, una radiodifusora cristocéntrica, ubicada en Ocosingo, fue capaz de reunir 300 mil pesos en dos meses para comprar un transformador, con la 
aportación voluntaria de sus radioescuchas que pertenecen a diferentes denominaciones. Esto habla del apoyo que goza de su auditorio.

Las radios zapatistas, con un perfil ideológico muy definido, no tienen como finalidad los anuncios comerciales, tampoco las estaciones de corte municipal, partidista. Viven de sus bases, las primeras, y de los ayuntamientos las otras. Las comunitarias sí emiten algunos anuncios, pero a bajo costo y están ubicadas en zonas de difícil acceso, que no representan competencia real para la radio comercial.

\section{Música y programación}

Cada tipo de estación perfila una barra programática particular. La radio comunitaria, por ejemplo, sobre todo la que impulsa Boca de Polen en las comunidades indígenas de Chiapas, se preocupa por transmitir programas relacionados con el desarrollo local, la sana convivencia con el medio ambiente y las posibilidades de obtener buenas cosechas con la adopción de mejores técnicas de cultivo. La música que transmite es de la región, a veces, con participaciones en vivo desde el estudio.

Las radios comerciales no concesionadas, municipales y partidistas emiten música de cantantes del momento, sobre todo baladas, pop y bandas norteñas. Los programas son de entretenimiento, pero a las últimas las distingue por hacer referencia a las actividades del ayuntamiento o del partido político al que pertenecen.

En cuanto a la radio religiosa tiene una programación variada. Las católicas poseen en común la oración del Ángelus, del Santo Rosario, laudes y misas, así como la difusión del Informativo para Hispanoamérica, producido por Radio Vaticano. El Ángelus, como lo hace la Cadena de Ondas Populares Españolas (COPE), se transmite tres veces al día. La diferencia fundamental entre las radios adventistas y las evangélicas radica en la música. El patrón musical de la barra programática adventista descansa en la música que denominan "de edificación", en donde no existe prácticamente la copia de canciones comerciales a las que solo se les ha alterado la letra. Es un estilo que los ha marcado desde la forma misma de celebración del culto: nada de gritos, exclamaciones y regaños elevados a todos los decibeles.

En cambio, las radios cristocéntricas o cristianas evangélicas proponen en términos generales un cristianismo "vivo", "emotivo", "festivo", debido a que sus rituales están cargados de expresiones corporales y orales que son acompañados con cantos y música (Rivera y otros, 2012: 84).

Los géneros musicales que se transmiten son tan variados como los existentes en la música comercial. "Pasamos todos los géneros musicales, siempre y cuando hablen de Cristo" (Sántiz, 2012). Cada radio, dependiendo su denominación, conserva su perfil: festivo, ceremonioso o espiritual, porque al fin y al cabo las estaciones son prolongaciones de los púlpitos, una extensión que lleva una marca y una doctrina que coexiste con otras pero que debe diferenciarse para el consumo de los fieles. 


\section{Conclusiones}

Durante 70 años la radio, sobre todo la comercial, mantuvo una hegemonía en el espectro radiofónico. Las causas eran diversas pero se debían, fundamentalmente, a la tecnología poco accesible y a una influencia política que evitaba la incursión de grupos minoritarios. Establecer una radiodifusora en los años ochenta estaba al alcance de pocos, porque se requería cerca de 10 millones de pesos; en la actualidad, se gastan entre 50 mil y cien mil pesos en infraestructura.

Estas radiodifusoras requieren baja inversión: las cabinas, en general, son improvisadas, y las consolas y los transmisores son usados y de poca potencia. Cuatro de ellas cuentan con estudios y equipos profesionales. Las radiodifusoras no concesionadas cuentan, además, con un aliado fundamental: los celulares y la Internet, que les permite abaratar costos. A través de los teléfonos reciben solicitudes de canciones, saludos y publicidad; con Internet se abastecen de música, intercambian programas y emiten contenidos más allá de su localidad.

Estas radios no constituyen un estupendo negocio. Se convierten en un medio de subsistencia y, a veces, de influencia en la comunidad, pero nada más. Si es así, ¿por qué existe una preocupación tan alarmante, por parte de los empresarios radiofónicos, por la multiplicación de este tipo de radiodifusoras? Primero, porque vislumbran una fragmentación del mercado radiofónico con la consecuente pérdida de presencia e influencia en las poblaciones chiapanecas, en donde el vehículo de información ha sido preponderantemente la radio, por encima de la televisión.

Sin embargo, en el aspecto económico, los grupos radiales resultan poco perjudicados. Si acaso, la ausencia de programas religiosos por los que antes cobraban y que ahora están ausentes de su barra programática. Las radios comerciales no concesionadas disputan plazas menores y perjudican a pequeños empresarios radiofónicos. San Cristóbal de Las Casas, por ejemplo, se ha convertido en un espacio de disputa entre un empresario, con apenas una concesión y un permiso, y varias estaciones comerciales sin concesión.

Estas radiodifusoras, pese a que lucran con el espectro, ofrecen precios muy accesibles por sus comerciales. Se anuncian en ellas la vendedora de tamales de la esquina, la panadera, el carnicero, el tendero, la señora que vende garnachas por la noche o la que promueve productos de belleza. No quedan excluidos, por supuesto, negocios de mayor tamaño: zapaterías, farmacias, embotelladoras de agua o institutos escolares, pero la persona que trabaja sola, y que antes utilizaba altoparlantes para anunciar su mercancía, ahora emplea la radio para llegar a un mayor número de posibles compradores.

La radio sin concesión ha sustituido en los pueblos a los medios tradicionales, sin las molestias que generaba el altoparlante de hacerse oír sin límites. Esta radio, al igual que ese antiguo medio, se emplea ahora para anunciar los pequeños acontecimientos de la comunidad, no solo con la promoción de productos para el consumo, sino para enviar saludos, informar de bodas, decesos o disposiciones municipales. No es raro, y más bien de 
uso corriente, que las autoridades de todos los niveles empleen a esta radio para promover campañas culturales, deportivas, sociales, de alfabetización y de salud.

Las radios al margen no cierran sus espacios a las campañas de los gobiernos municipal, estatal o federal. Es más, de esa manera se sienten arropados por las autoridades y con argumentos para indicar que prestan servicios a la comunidad. Buscan resquicios para permanecer y ser reconocidas en un marco legal que no propicia la incursión de actores nuevos. Todas aspiran a contar con mayor seguridad y certeza jurídica. Muchas no invierten en infraestructura porque saben que podrían ser decomisadas en cualquier momento.

No encontramos ninguna radiodifusora que aliente la violencia o que sea utilizada por grupos de delincuencia organizada. Suponemos que para los narcotraficantes o secuestradores, la radio no es un buen medio para transmitir sus mensajes. Ellos emplean tecnología más moderna que sea difícilmente detectable por las autoridades. Es posible, desde luego, que en el mar de radios al margen de México algunas sean financiadas por grupos delincuenciales, pero en Chiapas no hay evidencias de este tipo, pese a su condición de frontera.

En cuanto al personal, estas radios se apoyan en los jóvenes. Muchachos que, sin preparación ni sueldo, se lanzan emocionados a hablar de artistas, de futbolistas, de amigos y no dudan en tratar de "educar" o de "convertir" a su auditorio. Por eso, en los operativos, los detenidos son siempre jóvenes (muchas veces menores de edad), aprendices de locutores, que han encontrado en el micrófono una vía para manifestar sus pasiones. De ahí que la programación no se diferencie de una estación comercial legalmente establecida. Se le imita, casi siempre, con defectos multiplicados.

La emergencia y permanencia de las radios no concesionadas no debe significar, tampoco, un cheque en blanco para su existencia indiscriminada, pero sí deben ofrecerse las condiciones y las garantías para la operación ordenada de este tipo de radiodifusoras. En algunas ciudades, la multiplicidad de emisiones se convierte un problema para todas las radiodifusoras. San Cristóbal de Las Casas, decíamos, es el ejemplo paradigmático: ahí conviven estaciones concesionadas, permisionadas, religiosas y zapatistas. Los propios protagonistas de las radios al margen de ese lugar claman por el control de las radiodifusoras.

Este crecimiento caótico solo podrá evitarse con una legislación que reconozca otro tipo de manifestaciones radiales, y eso en parte lo subsana la Ley de Telecomunicaciones de 2013. En Estados Unidos, desde los inicios de la radiodifusión, se permitió la existencia de estaciones religiosas y en Centro y Sudamérica se han impulsado radiodifusoras comunitarias.

El propósito de este trabajo es enriquecer la discusión y conocer la postura de los protagonistas de las radios que ahora están en el margen legal. El nuevo marco permite la operación de radiodifusoras que emerjan desde las comunidades, que sean un vehículo alternativo de comunicación y que propicien la sana convivencia. No es posible desaparecer a estas radiodifusoras, por los posibles conflictos sociales que pueden ocasionarse y por 
la facilidad técnica de establecerlas, pero sí se puede normar su existencia y encauzarlas a cumplir con tareas que busquen el desarrollo de la región y de sus habitantes.

Este trabajo es solo una radiografía del complejo fenómeno de las radios no concesionadas, en la que Chiapas se alza como protagonista principal en México.

\section{Fuentes consultadas}

Anuncios Radios (2008, julio 24). "Las radios ilegales en España alcanzan las 2.300". Extraída el 28/I/2015 desde http://www.anuncios-radio.com/web/noticias/las-radiosilegales-en-espana-alcanzan-las-2.300la-emision-musical-3.html

Bravo, J. (ed.) (2011). Panorama de la comunicación en México 2011. Desafíos para la calidad y la diversidad. México D. F.: Amedi.

Calleja, A. y Solís, B. (2007). Con permiso. La radio comunitaria en México. México D. F.: Amedi.

Custodio, C. (2008, diciembre 14). "Cancelan ocho radios cristianas en Chiapas, México". Extraída el 28/I/2015 desde http://proyectoaltar.com/2008/12/14/cancelan-ocho-radioscristianas-en-chiapas-mexico/

El Informador (2010, octubre 29). "Estaciones de radio piratas en Chiapas desmanteladas". Extraída el 28/I/2015 desde http:/www.informador.com.mx/mexico/2010/237387/6/ estaciones-de-radio-piratas-en-chiapas-desmanteladas.htm

Enlace Zapatista (2011, febrero 3). "Radios libres para Chiapas". Extraída el 28/I/2014 desde https://www.youtube.com/watch?v=hTn-9xfKch0

Gómez Mena, C. (2011, septiembre 7). "Buscan que Radio Tepeyac esté en FM”. Extraída el 28/I/2015 desde http://www.jornada.unam.mx/2011/09/07/sociedad/037n3soc

Henríquez, E. (2008, octubre 30). "Protestan 3 mil evangélicos en Chiapas por cierre de 8 radiodifusoras cristianas". Extraída el 28/I/2015 desde http://www.jornada.unam.mx/2008/ 11/30/index.php?section $=$ estados\&article $=035$ n 1 est

Hernández Alcántara, M. (2011, junio 24). “Cofetel ha desmantelado 380 'radios piratas' de 2004 a la fecha”. Extraída el 28/I/2015 desde http://www.jornada.unam.mx/2011/ 06/24/ economia/031n 3 eco

Martínez, S.; Villar, H.; Cordero, F. y Matus, J. (2013). Radios al margen. Frecuencias no concesionadas en Chiapas. Chiapas: Cecol Editorial. 
Mejía Barquera, F. (2011, septiembre 10). "90 años de radio en México”. Extraída el 28/I/2015 desde http://www.etcetera.com.mx/articulo.php?articulo=9009

Noticia Cristiana, portal de noticias.

_(2009, julio 29). "Comienza el decomiso de radios cristianas en México". Extraída el 28/I/2015 desde http://www.noticiacristiana.com/sociedad/persecuciones/2009/07/ comienza-el-decomiso-de-radios-cristianas-en-mexico.html

_(2008a, septiembre 24). "Se realizó gran marcha pacífica de evangélicos en San Cristóbal de las Casas Chiapas, México". Extraída el 28/I/2015 desde http://www.noticiacristiana. com/ iglesia/2008/09/se-realizo-gran-marcha-pacifica-de-evangelicos-en-san-cristobalde-las-casas-chiapas-mexico.html

_(2008b, diciembre 1). "3 mil evangélicos protestan en Chiapas por cierre de 8 radiodifusoras cristianas". Extraída el 28/I/2015 desde http://www.noticiacristiana.com/ sociedad/2008/12/3-mil-evangelicos-protestan-en-chiapas-por-cierre-de-8-radiodifusorascristianas.html

Radio Insurgente (2015, enero 25). “Quiénes somos”. Extraída el 28/I/2015 desde http:// www.radioinsurgente.org/index.php?name=QuienesSomos

Rivera, C. y otros (2012). Diversidad religiosa y conflicto en Chiapas: intereses, utopias y realidades. México D. F.: Universidad Nacional Autónoma de México, Consejo de Ciencia y Tecnología del Estado de Chiapas.

Romero, G. (2008). La construcción de espacios públicos en México: Las radios comunitarias y su participación en la democratización de los medios electrónicos. México D. F.: FLACSO.

Sántiz Gómez, M. (2012, enero 22). Encargado de Radio Jeshúa. Entrevista personal.

Sierra Sánchez, J. (2010). "Estudio de la oferta de programación de las radios autonómicas en España”. Extraída el 28/I/2015 desde http://www.revistalatinacs.org/10/art2/906_UAO/ 28 Sierra.html

YouTube (2011, septiembre 5). "Rueda de Prensa. Mons. Felipe A." [Felipe Arizmendi Esquivel]. Extraía el 28/I/2015 desde http:/www.youtube.com/watch?v=-YQCSk4Y2U4 